\title{
Design Manufacturing and Cost Estimation of Camshaft Used In Two Wheeler
}

\author{
${ }^{1}$ V. Mallikarjuna, ${ }^{2}$ N. Jashuva, ${ }^{3}$ G. Nagaraju, ${ }^{4}$ B. Rama Bhupal Reddy \\ ${ }^{1}$ Assistant Professor, Department of Mechanical Engineering, Global College of Engineering, Science \& \\ Technology, Kadapa, A.P., India. \\ ${ }^{2}$ Assistant Professor, Department of Humanities, Bharat College of Engineering \& Technology for Women, \\ Kadapa, A.P., India \\ ${ }^{3}$ Assistant Professor, Department of Mechanical Engineering, Sreenivasa College of Engineering \& \\ Technology, Laxmipuram, Kurnool, A.P., India. \\ ${ }^{4}$ Associate Professor, Department of Mathematics, K.S.R.M. College of Engineering, Kadapa, A.P., India.
}

\begin{abstract}
The camshaft and its associated parts control the opening and closing of the two valves. The associated parts are push rods, rocker arms, valve springs and tappets. This shaft also provides the drive to the ignition system. The camshaft is driven by the crankshaft through timing gears. Cams are made as integral parts of the camshaft and are designed in such a way to open the valves at the correct timing and to keep them open for the necessary duration. In this project, a camshaft is designed for a two wheeler engine by using theoretical calculations. Cam profile is designed by using the calculations. A 3D model of the Camshaft is created using modeling software Pro/Engineer. For manufacturing cam shaft following manufacturing method are used by Machining, Casting and Forging. From above processes we selected casting processes because it's used for bulk production. For the manufacture of Camshaft Core and Cavity is to be extracted from the model using manufacturing module in Pro/Engineer. Total Mould base is to be designed for the camshaft which is ready to go for production. CNC Program is to be generated for both core and cavity using roughing and finishing processes. This is also done in manufacturing module in Pro/Engineer. Total cost required for the manufacturing of die is estimated. From this project we will learn a manufacturing method for camshaft. Pro/ENGINEER is the standard in $3 D$ product design, featuring industry-leading productivity tools that promote best practices in design.
\end{abstract}

Key words: CAD/CAM/CAE, ANSYS, CFD, CAMSHAFT, DIE CASTING

\section{Introduction to Camshaft}

A camshaft is a shaft to which a cam is fastened or of which a cam forms an integral part. In internal combustion engines with pistons, the camshaft is used to operate poppet valves. It then consists of a cylindrical rod running the length of the cylinder bank with a number of oblong lobes protruding from it, one for each valve. The cams force the valves open by pressing on the valve, or on some intermediate mechanism as they rotate.

\section{Automotive Material Camshafts can be made out of several different types of material. These include:}

Chilled iron castings: this is a good choice for high volume production. A chilled iron camshaft has a resistance against wear because the camshaft lobes have been chilled, generally making them harder. When making chilled iron castings, other elements are added to the iron before casting to make the material more suitable for its application.

Billet Steel: When a high quality camshaft is required, engine builders and camshaft manufacturers choose to make the camshaft from steel billet. This method is also used for low volume production. This is a much more time consuming process, and is generally more expensive than other methods. However the finished product is far superior. When making the camshaft, $\mathrm{CNC}$ lathes, $\mathrm{CNC}$ milling machines and $\mathrm{CNC}$ camshaft grinders will be used.

Timing: The relationship between the rotation of the camshaft and the rotation of the crankshaft is of critical importance. Since the valves control the flow of air/fuel mixture intake and exhaust gases, they must be opened and closed at the appropriate time during the stroke of the piston. For this reason, the camshaft is connected to the crankshaft either directly, via a gear mechanism, or indirectly via a belt or chain called a timing belt or timing chain.

Duration: Duration is the number of crankshaft degrees of engine rotation during which the valve is off the seat. As a generality, greater duration results in more horsepower. The RPM at which peak horsepower occurs is typically increased as duration increases at the expense of lower rpm efficiency (torque). Duration can often be confusing because manufacturers may select any lift point to advertise a camshaft's duration and sometimes will 
manipulate these numbers. The power and idle characteristics of a camshaft rated at .006 " will be much different than one rated the same at .002 ". Many performance engine builders gauge a race profile's aggressiveness by looking at the duration at $.020 ", .050 "$ and $.200 "$ ". The .020 " number determines how responsive the motor will be and how much low end torque the motor will make. The .050 " number is used to estimate where peak power will occur, and the .200 " number gives an estimate of the power potential.

Lift: The camshaft "lift" is the resultant net rise of the valve from its seat. The further the valve rises from its seat the more airflow can be realized, which is generally more beneficial. Greater lift has some limitations. Firstly, the lift is limited by the increased proximity of the valve head to the piston crown and secondly greater effort is required to move the valve's springs to higher state of compression. Increased lift can also be limited by lobe clearance in the cylinder head construction, so higher lobes may not necessarily clear the framework of the cylinder head casing. Higher valve lift can have the same effect as increased duration where valve overlap is less desirable.

Position Depending on the location of the camshaft, the cams operate the valves either directly or through a linkage of pushrods and rockers. Direct operation involves a simpler mechanism and leads to fewer failures, but requires the camshaft to be positioned at the top of the cylinders. In the past when engines were not as reliable as today this was seen as too much bother, but in modern gasoline engines the overhead cam system, where the camshaft is on top of the cylinder head, is quite common.

Number of camshafts While today some cheaper engines rely on a single camshaft per cylinder bank, which is known as a single overhead camshaft (SOHC), most modern engine designs (the overhead-valve or OHV engine being largely obsolete on passenger vehicles), are driven by a two camshafts per cylinder bank arrangement (one camshaft for the intake valves and another for the exhaust valves); such camshaft arrangement is known as a double or dual overhead cam (DOHC), thus, a V engine, which has two separate cylinder banks, may have four camshafts (colloquially known as a quad-cam engine).

\section{Working of Camshaft}

The camshaft uses lobes (called cams) that push against the valves to open them as the camshaft rotates; springs on the valves return them to their closed position. This is a critical job, and can have a great impact on an engine's performance at different speeds. On the next page of this article you can see the animation we built to really show you the difference between a performance camshaft and a standard one.

\section{Camshaft Basics}

The key parts of any camshaft are the lobes. As the camshaft spins, the lobes open and close the intake and exhaust valves in time with the motion of the piston. It turns out that there is a direct relationship between the shape of the cam lobes and the way the engine performs in different speed ranges. To understand why this is the case, imagine that we are running an engine extremely slowly -- at just 10 or 20 revolutions per minute (RPM) -- so that it takes the piston a couple of seconds to complete a cycle. It would be impossible to actually run a normal engine this slowly, but let's imagine that we could. At this slow speed, we would want cam lobes shaped so that:

- Just as the piston starts moving downward in the intake stroke (called top dead center, or TDC), the intake valve would open. The intake valve would close right as the piston bottoms out.

- The exhaust valve would open right as the piston bottoms out (called bottom dead center, or BDC) at the end of the combustion stroke, and would close as the piston completes the exhaust stroke. .

There are several different arrangements of camshafts on engines.

- Single overhead cam (SOHC)

- Double overhead cam (DOHC)

- Pushrod

\section{Camshaft Configurations \\ Single Overhead Cam}

This arrangement denotes an engine with one cam per head. So if it is an inline 4-cylinder or inline 6cylinder engine, it will have one cam; if it is a V-6 or V-8, it will have two cams (one for each head). On single and double overhead cam engines, the cams are driven by the crankshaft, via either a belt or chain called the timing belt or timing chain. These belts and chains need to be replaced or adjusted at regular intervals. If a timing belt breaks, the cam will stop spinning and the piston could hit the open valves. 


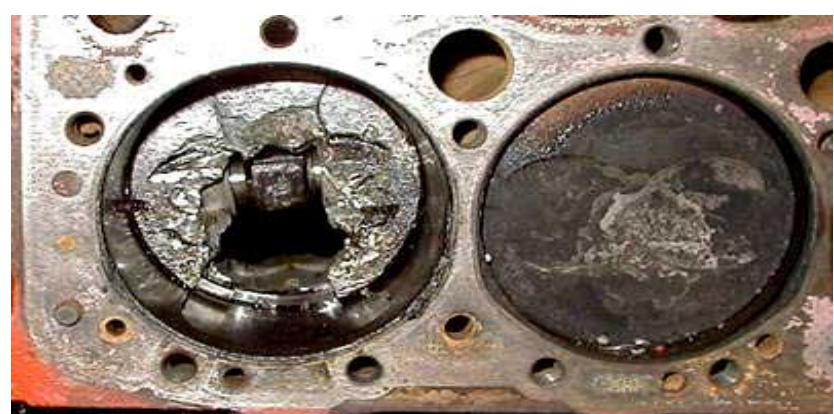

Figure 1: Damage from a piston striking a valve

The picture above shows what can happen when a piston hits an open valve.

\section{Double Overhead Cam}

A double overhead cam engine has two cams per head. So inline engines have two cams, and $\mathrm{V}$ engines have four. Usually, double overhead cams are used on engines with four or more valves per cylinder -- a single camshaft simply cannot fit enough cam lobes to actuate all o those valves.

The main reason to use double overhead cams is to allow for more intake and exhaust valves. More valves means that intake and exhaust gases can flow more freely because there are more openings for them to flow through. This increases the power of the engine.

Pushrod Engines

Like SOHC and DOHC engines, the valves in a pushrod engine are located in the head, above the cylinder. The key difference is that the camshaft on a pushrod engine is inside the engine block, rather than in the head.

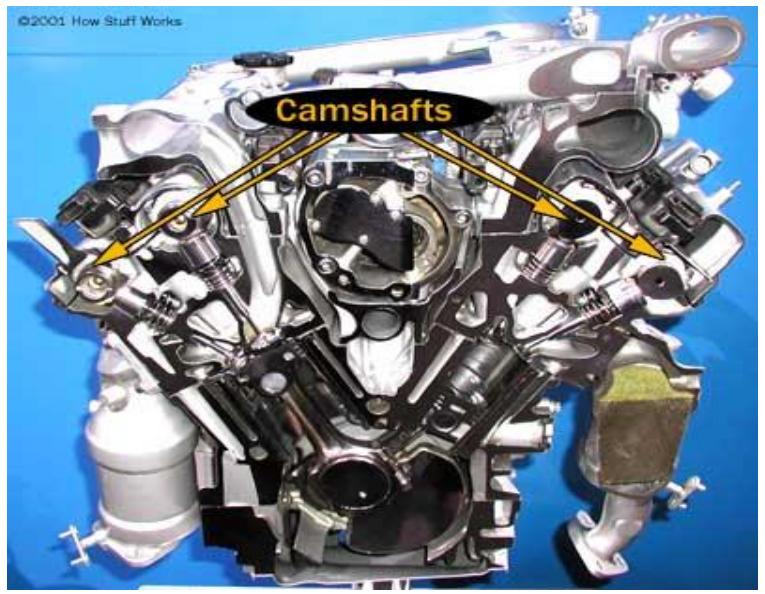

Figure 2: Camshafts

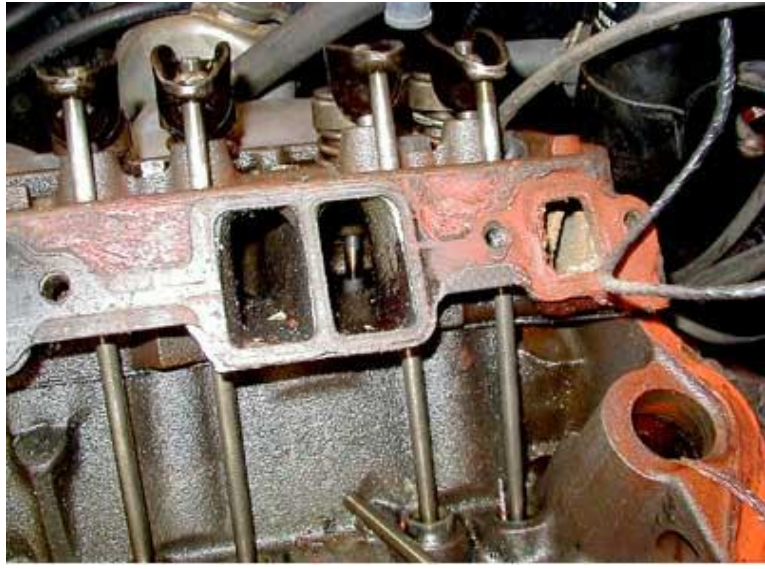

Figure 3: A pushrod engine

\section{Variable Valve Timing}

There are a couple of novel ways by which carmakers vary the valve timing. One system used on some Honda engines is called VTEC.
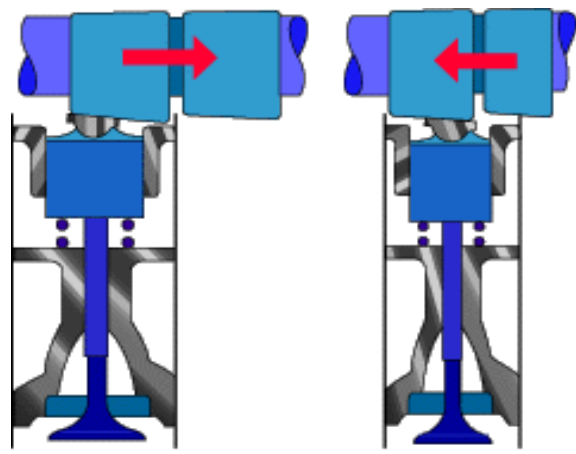

Figure 4: The variable cam system used on some Ferraris 
VTEC (Variable Valve Timing and Lift Electronic Control) is an electronic and mechanical system in some Honda engines that allows the engine to have multiple camshafts. VTEC engines have an extra intake cam with its own rocker, which follows this cam. The profile on this cam keeps the intake valve open longer than the other cam profile. At low engine speeds, this rocker is not connected to any valves. At high engine speeds, a piston locks the extra rocker to the two rockers that control the two intake valves.

Camshaft Design Camshaft design today is an extremely complex process employing the use of computers in every phase of design analysis and testing not to mention the years of experience required to make these phases become reality. As complex as it is however, camshaft design, in its simplest form, may be broken down into two segments.

The first segment involves lobe placement on the camshaft. This establishes the very critical valve train event timing in relation to piston and crankshaft positions. It also establishes the displacement or separation of the intake lobe in relation to the exhaust. This placement is very critical and must be exactly the same for each cylinder.

The second segment involves designing the lobe and clearance ramp profiles. By far, this is the most critical and difficult segment of camshaft design. In today's race engines you must develop a lobe profile that is aggressive enough to produce the desired rate of lift yet smooth enough to avoid new valve train problems.

\section{About Cam}

A cam is a rotating or sliding piece in a mechanical linkage used especially in transforming rotary motion into linear motion or vice-versa. It is often a part of a rotating wheel (e.g. an eccentric wheel) or shaft (e.g. a cylinder with an irregular shape) that strikes a lever at one or more points on its circular path. The cam can be a simple tooth, as is used to deliver pulses of power to a steam hammer, for example, or an eccentric disc or other shape that produces a smooth reciprocating (back and forth) motion in the follower, which is a lever making contact with the cam.

\section{Theoretical Calculations of Camshaft}

For $150 \mathrm{cc} 4$ Stroke IC engine

$\mathrm{D}=$ Diameter of bore $=57 \mathrm{~mm}$

$1=$ stroke $=58.6 \mathrm{~mm} \quad($ length of stroke $)$

Area of piston $a=\frac{\pi}{4} D^{2}=\frac{\pi}{4}(57)^{2}$

Velocity of piston $V=\frac{2 \pi N}{60}=\frac{2 \times 58.6 \times 6000}{60}=11720 \mathrm{~mm} / \mathrm{s}$

Area of part $=a_{p}$

$\mathrm{V}_{\mathrm{p}}=$ mean velocity of gas flowing through part

$\mathrm{V}_{\mathrm{p}}=90 \mathrm{~m} / \mathrm{s}=90000 \mathrm{~mm} / \mathrm{s}$

$\mathrm{a}_{\mathrm{p}} \mathrm{v}_{\mathrm{p}}=\mathrm{av}$

$a_{p}=\frac{a v}{v_{p}}=\frac{1550.465 \times 11720}{90000}$

$a_{p}=\frac{\pi}{4} d_{p}^{2}$

$\mathrm{d}_{\mathrm{p}}=$ diameter of part

$332.12=\frac{\pi}{4} d_{p}^{2}$

$\mathrm{d}_{\mathrm{p}}=20.56 \mathrm{~mm}$

Diameter of valve $d_{v}=32.33 \mathrm{~mm}$

Maximum lift of the valve

$$
\begin{aligned}
& \alpha=30^{\circ} \\
& h=\frac{d_{p}}{4 \cos \alpha}=\frac{20.56}{4 \cos \alpha}=5.93
\end{aligned}
$$

\section{Design of Camshaft}

The cam is forged as one piece with the camshaft

The diameter of camshaft 


$$
\begin{aligned}
& \mathrm{D}^{1}=0.16 \times \text { cylinder bore }+12.7 \\
& \mathrm{D}^{1}=0.16 \times 57+12.7=21.82 \mathrm{~mm}
\end{aligned}
$$

The base circle diameter is about $4 \mathrm{~mm}$ greater than camshaft diameter

Base circle diameter $=21.82+3=24.82 \mathrm{~mm}=25 \mathrm{~mm}$

Width of camshaft $\quad \mathrm{w}^{1}=0.09 \times$ cylinder bore +6

$\mathrm{W}^{1}=0.09 \times 57+6=11.13 \mathrm{~mm}$

$\mathrm{OA}=$ minimum radius of camshaft $+(1 / 2 \times$ diameter of roller $)$

$$
=12.5+(1 / 2 \times 41)=33 \mathrm{~mm}
$$

\section{Design of Key}

$\mathrm{D}^{1}=21.82 \mathrm{~mm}$

Width of key $\mathrm{w}=0.25 \mathrm{D}^{1}=5.455 \mathrm{~mm}$

Thickness of key $\mathrm{t}=0.66 \mathrm{w}=3.6 \mathrm{~mm}$

Length of key $1=\mathrm{D}+1.5 \mathrm{D}=21.82=22 \mathrm{~mm}$

Gas pressure $=15.454 \mathrm{~N} / \mathrm{mm}^{2}$

Compression ratio $=10: 1$

So cylinder pressure and suction pressure is 10 times less than the gas pressure

$$
\mathrm{P}_{\mathrm{c}}=\mathrm{P}_{\mathrm{s}}=1.545 \mathrm{~N} / \mathrm{mm}^{2}
$$

\section{Process}

The following are the four steps in traditional die casting, also known as high-pressure die casting; these are also the basis for any of the die casting variations: die preparation, filling, ejection, and shakeout. The dies are prepared by spraying the mold cavity with lubricant. The lubricant both helps control the temperature of the die and it also assists in the removal of the casting. The dies are then closed and molten metal is injected into the dies under high pressure; between 10 and 175 mega Pascal (1,500 and 25,400 psi). Once the mold cavity is filled, the pressure is maintained until the casting solidifies. The dies are then opened and the shot (shots are different from castings because there can be multiple cavities in a die, yielding multiple castings per shot) is ejected by the ejector pins. Finally, the shakeout involves separating the scrap, which includes the gate, runners, spurs and flash, from the shot. This is often done using a special trim die in a power press or hydraulic press. Other methods of shaking out include sawing and grinding. A less labor-intensive method is to tumble shots if gates are thin and easily broken; separation of gates from finished parts must follow. This scrap is recycled by remelting it. The yield is approximately $67 \%$.

Inspection: After the shakeout of the casting it is inspected for defects. The most common defects are misruns and cold shuts. These defects can be caused by bold dies, low metal temperature, dirty metal, lack of venting, or too much lubricant. Other possible defects are gas porosity, shrinkage porosity, hot tears, and flow marks. Flow marks are marks left on the surface of the casting due to poor gating, sharp corners, or excessive lubricant.

Lubricants: Water-based lubricants, called emulsions, are the most commonly used type of lubricant, because of health, environmental, and safety reasons. Unlike solvent-based lubricants, if water is properly treated to remove all minerals from it, it will not leave any by-product in the dies. If the water is not properly treated, then the minerals can cause surface defects and discontinuities. There are four types of water-based lubricants: oil in water, water in oil, semi-synthetic, and synthetic. Oil in water is the best, because when the lubricant is applied the water cools the die surface by evaporating while depositing the oil, which helps release the shot. A common mixture for this type of lubricants is thirty parts water to one part oil, however in extreme cases a ratio of 100:1 is used.

Variants Acurad: Acurad was a die casting process developed by General Motors in the late 1950s and 1960s. The name is an acronym for accurate, reliable, and dense. It was developed to combine a stable fill and directional solidification with the fast cycle times of the traditional die casting process. The process pioneered four breakthrough technologies for die casting: thermal analysis, flow and fill modeling, heat treatable and high integrity die castings, and indirect squeeze casting.

Pore-free: When no porosity is required for a casting then the pore-free casting process is used. It is identical to the standard process except oxygen is injected into the die before each shot to purge any air from the mold cavity. This causes small dispersed oxides to form when the molten metal fills the dies, which virtually eliminates gas porosity. An added advantage to this is greater strength. Unlike standard die castings, these castings can be heat treated and welded. This process can be performed on aluminum, zinc, and lead alloys.

Heated-manifold direct-injection die casting, also known as direct-injection die casting or runnerless die casting, is a zinc die casting process where molten zinc is forced through a heated manifold and then through heated mini-nozzles, which lead into the molding cavity. This process has the advantages of lower cost per part, 
through the reduction of scrap (by the elimination of spurs, gates and runners) and energy conservation, and better surface quality through slower cooling cycles.

Semi-solid: Semi-solid die casting uses metal that is heated between its liquids and solids, so that it is "slushy". This allows for more complex parts and thinner walls.

\section{Design aspects of die casting}

- Since the metallic mold of a die casting expands when it is filled with a molten metal and then both the casting and the mold shrinks during cooling the shrinkage allowances taken in the die mold design are smaller than those in the Sand casting.

- Parts of $0.05 \mathrm{lb}(20 \mathrm{~g})$ to $75 \mathrm{lb}(34 \mathrm{~kg})$ may be cast.

- The section thickness of permanent mold casting may vary in the range 0.02 " - 0.5" (0.5-12 mm).

- The dimensional tolerances are 0.01-0.03" (0.25-0.75 mm) depending on the casting section thickness.

- Allowances of 0.004-0.01" (0.1-0.25 mm) are taken for the dimensions crossing the parting line of the mold.

- $\quad$ The draft angle is commonly about $1 \%$.

\section{Core and Cavity}

Molds separate into at least two halves (called the core and the cavity) to permit the part to be extracted. In general the shape of a part must not cause it to be locked into the mold. For example, sides of objects typically cannot be parallel with the direction of draw (the direction in which the core and cavity separate from each other). They are angled slightly (draft), and examination of most plastic household objects will reveal this. Parts that are "bucket-like" tend to shrink onto the core while cooling, and after the cavity is pulled away. Pins are the most popular method of removal from the core, but air ejection, and stripper plates can also be used depending on the application. Most ejection plates are found on the moving half of the tool, but they can be placed on the fixed half.

\section{Core and Cavity Extraction in Pro/Engineer}

Select New - Manufacturing - Mold Cavity enter name - Change units - ok Assemble the Camshaft in to the manufacturing.

\section{Design Components:}

Moving housing: Moving housing is made out of Special grade cast iron to reduce machining. Threaded holes are provided on all sides for handling the piece using eyebolts. Weight reduction holes are provided without reducing the strength of the block. SMED slots and clamping slots are provided. Apart from ejector clamping, holes for bumper rods are also given.

Ejector guide pillar: Ejector guide pillar is made as a straight cylindrical rod that is fastened to insert backside. This makes easy manufacturing of the ejector guide pillar and loading. This arrangement gives more space by avoiding the ejector guide pillar retainer.

Support pillar: As there is no support for the cavity block other than sides, support pillars are provided to avoid buckling of cavity insert. This is made out of EN8

Ejector stopper: Ejector stopper is placed behind the return pins so that when the return pins takes the ejector assembly back and hits the housing, there should not be any moment which may cause buckling of the ejector plate.

Integral shot sleeve: Integral shot sleeve avoids the use of separate sprue bush and shot sleeve. It reduces the wear of plunger and gives interchangeability.

Insert clamp: As there is no support on sides of the inserts, clamps are provided on both sides of fixed and moving half. This is made a sliding type in order to reduce the die clamping time.

SMED arrangements are provided for the fast changing of the die.

1) $\mathrm{V}$ groove type: The bottom of the die contains a pair of $V$ groove whose mating part will be there in the machine. Machine contains an SMED bracket which is fixed with the help of dowels and screws. While loading the die, the die will seat on these brackets. As the bracket is fixed according to the position of the injection center, when the die seats on the bracket, the injection center of machine will be in line with the shot sleeve. 


\section{Create a work piece}

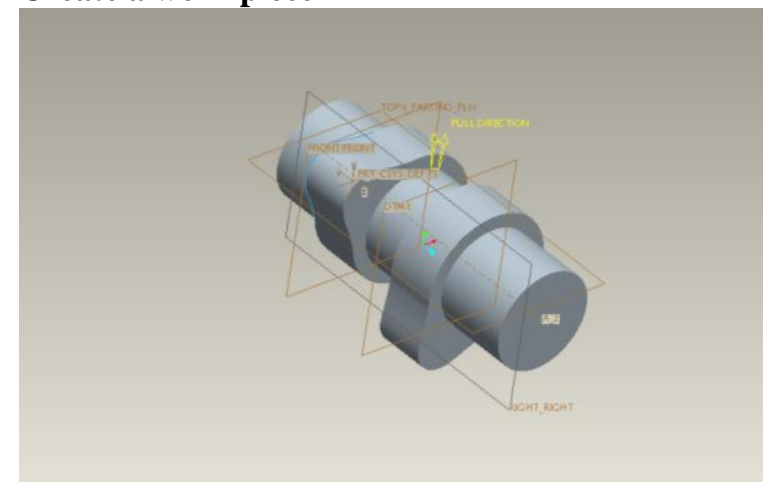

Cavity 2

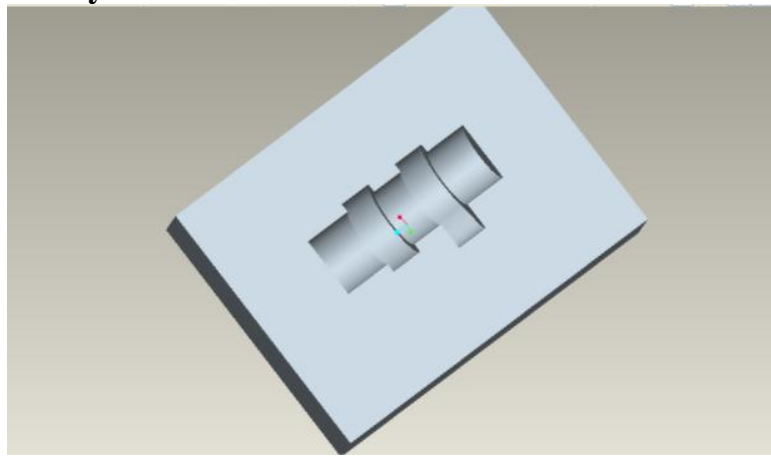

\section{DIE COMPONENTS}

\section{Cavity Block}

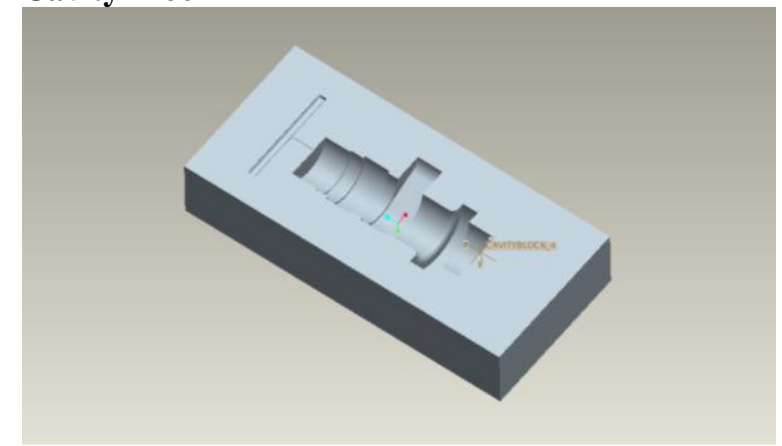

\section{Core Backplate}

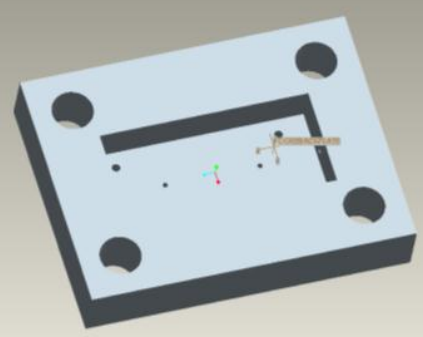

Ejector Plate

\section{Cavity 1}

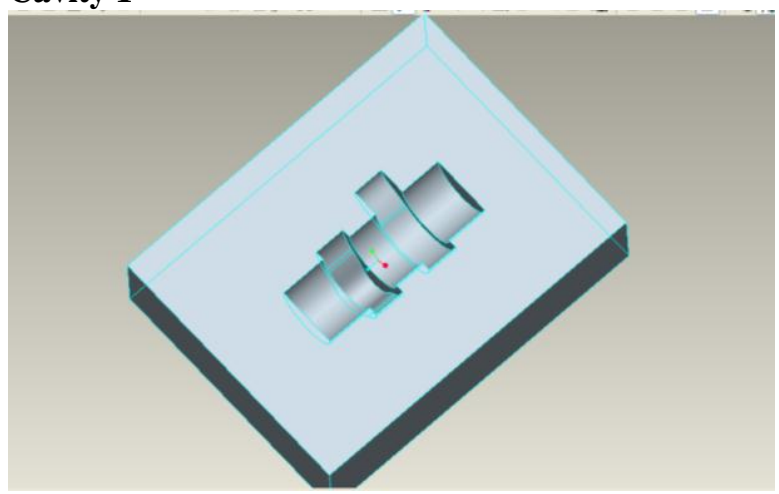

Core Block

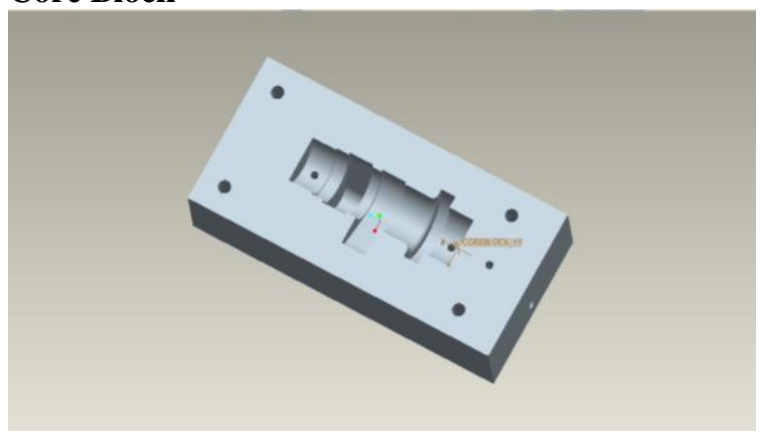

Spacer Housing

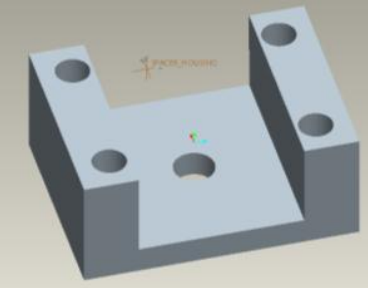



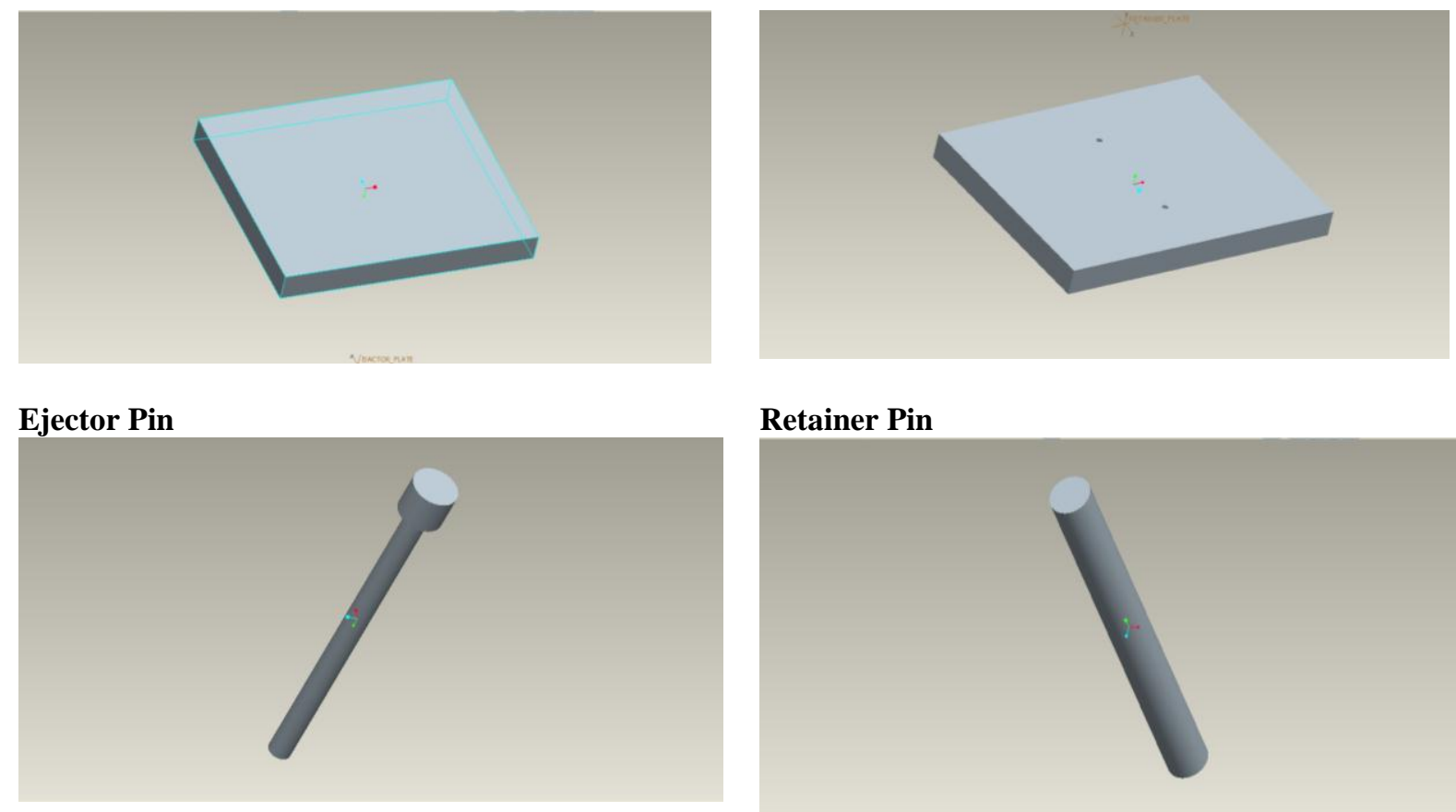

\section{Retainer Pin}

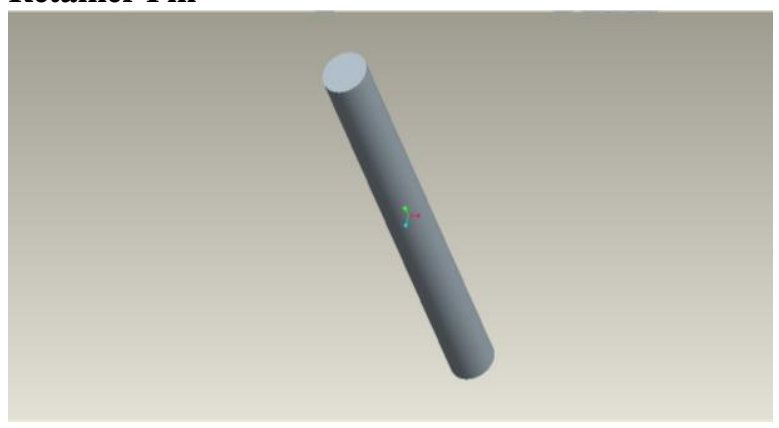

\section{Cavity Backplate}

\section{Piller}
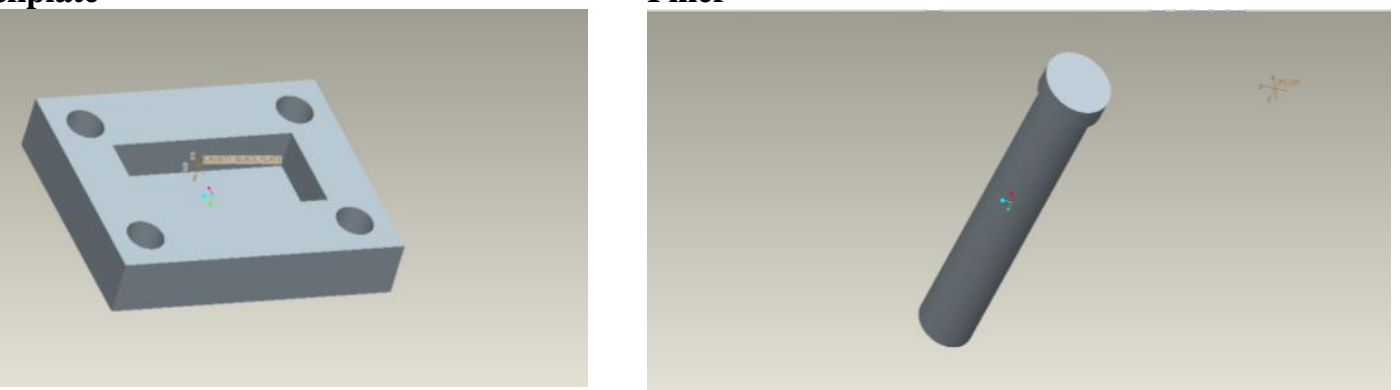

\section{Spacer Screw}

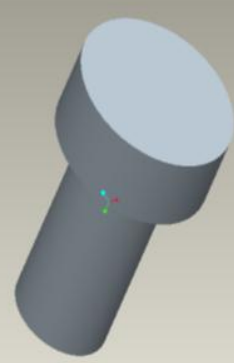

Total Assembly of Die Components

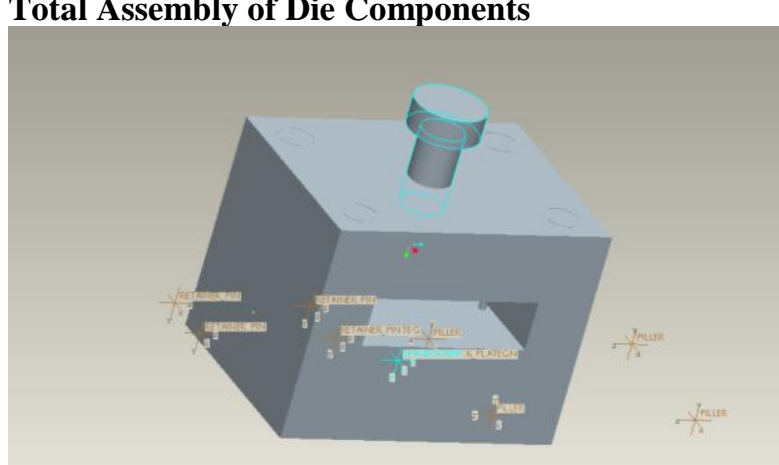

Drawings 

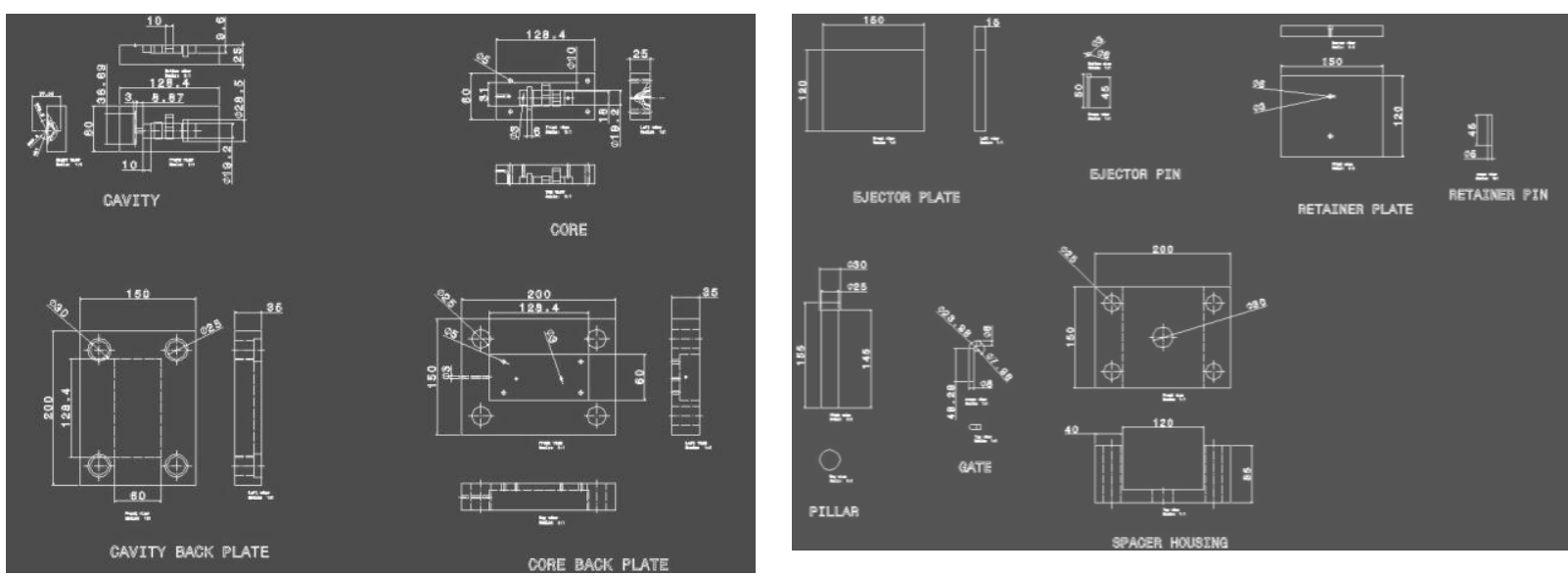

VII. Computer Aided Manufacturing in Pro/Engineer

By using the fundamental abilities of the software with regards to the single data source principle, it provided a rich set of tools in the manufacturing environment in the form of tooling design and simulated CNC machining and output. Tooling options cover specialty tools for molding, die-casting and progressive tooling design. Manufacturing lets you set up and run NC machines, create assembly process sequences, create bills of material, and generate inspection programs for Coordinate Measuring Machines (CMMs). Use the Manufacturing area is about streamlining the NC programming process for production milling of prismatic parts and multi surface three-axis milling. Manufacturing shows you how to program and set up your NC machines, create process flows that cover the $\mathrm{NC}$ operations as well as other operations, and define CMM inspection programs that probe manufactured parts.

\section{Procedure of Manufacturing}

For Cavity1

Select New - Manufacturing - NC Assembly - Enter name - Select units - ok

Retrieving the cavity 1 in to manufacturing

Set up the machine tool by selecting type of machine, cutting tool, Machine zero and retract.

For roughing, Select NC sequence - Machining - Volume - Done - Select tool and enter parameters like Cut feed, Step depth, Step over, Profile stock allow, rough stock allow, scan type and spindle speed.

Create volume.

Select Playpath

After completing Playpath, Select NC check

\section{Cavity1 in to manufacturing}

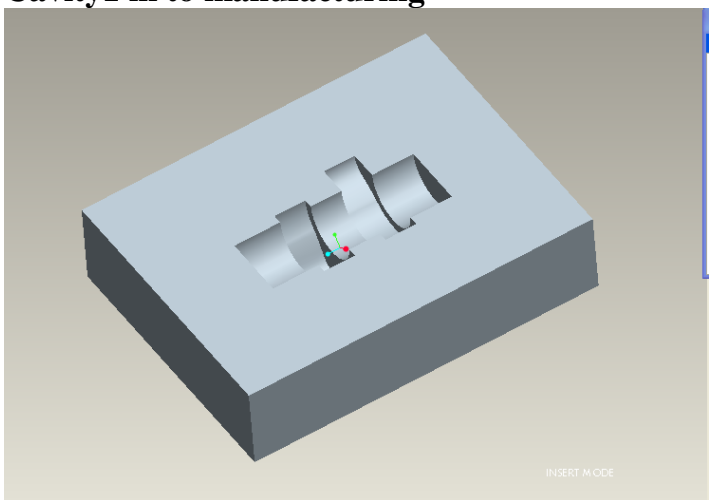

\section{After Completing playpath}

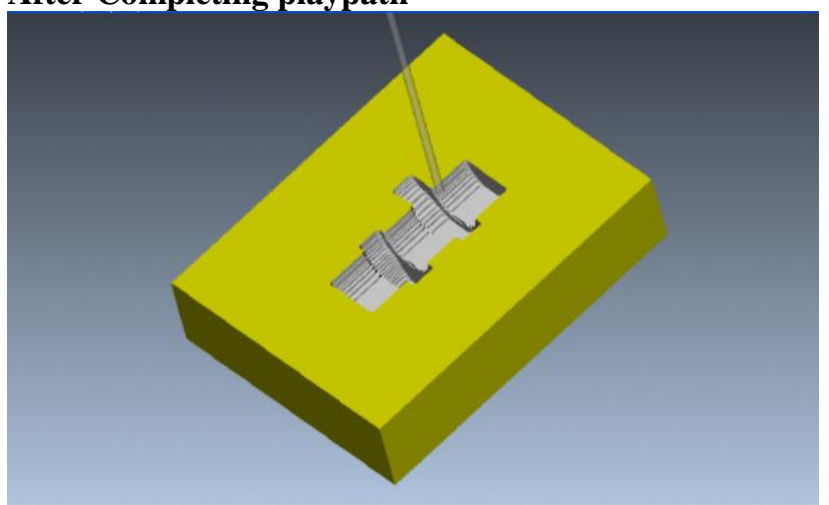

Machining $\rightarrow$ CL data $\rightarrow$ NC sequence $\rightarrow$ sequence $\rightarrow$ file $\rightarrow$ MCD file.

Done. Enter name . ok. Done.

\section{NC Program for roughing}

$\%$

G71

O0001

(D:Icamshaft_150ccłroughing_cavity1.ncl.1)

N0010T1M06
S3500M03

G00X-49.11Y-32.538

G43Z5.H01

$\mathrm{Z} 2$

G01Z-1.F300. 


X-55.24
Y-33.185
X-55.264Y-33.529
X-49.086
G03X-48.724Y-34.52I2.48J.342
G01X-55.625
G02X-56.815Y-35.512I-2.119J1.333
G01X-47.535
G03X-46.61Y-35.69I.929J2.325
G01X-32.5
Y-36.503
X-92.5
Y-37.494
X-32.5
Y-38.485
X-92.5
Y-39.476
X-32.5
Y-40.467
$X-92.5$
Y-41.458
$X-32.5$
$X-77.5$
Y-42.209
X-71.37
Y-41.289
$X-77.5$
Y-40.369
X-71.37
Y-39.449
X-77.5
Y-38.529

$X-71.37$
$X-77.5$
$Y-49.571$
$X-71.37$
$Y-38.529$
$Y-40.422$
$Z-12$.
$X-77.5$
$Y-41.329$
$X-71.37$
$Y-42.236$
$X-77.5$
$Y-43.143$
$X-71.37$
$Y-44.05$
$X-77.5$
$Y-44.957$
$X-71.37$
$Y-45.864$
$X-77.5$
$Y-46.771$
$X-71.37$
$Y-47.678$
$X-77.5$
$X-71.37$
$Y-40.422$
$X-77.5$
$Y-47.678$
$Z 5$.
$M 30$
$\%$

For finishing, Select NC sequence - Machining - Finishing - Done - Select tool and enter parameters like Cut feed, Step depth, Step over, Profile stock allow, scan type and spindle speed.

Create volume.

Select Playpath

After completing Plypath, Select NC check

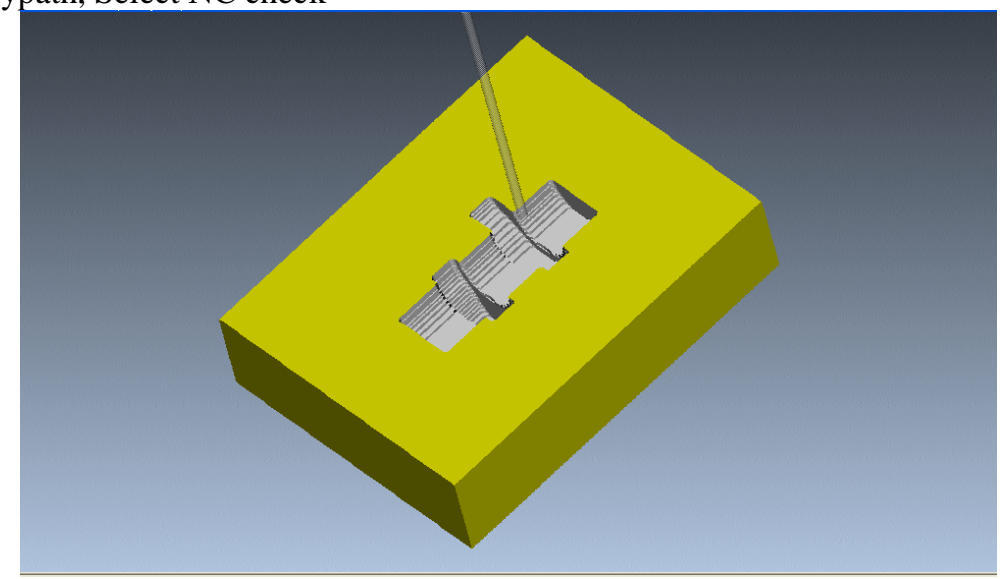

Machining $\rightarrow$ CL data $\rightarrow$ NC sequence $\rightarrow$ sequence $\rightarrow$ file $\rightarrow$ MCD file.

Done. Enter name . ok. Done.

\section{NC Program for Finishing}

$\%$

G71

O0002
(D:Icamshaft_150cclfinishing.ncl.1)

N0010T1M06 S7500M03 
G00X-62.329Y-94.259

G43Z5.H01

Z.6

G01Z0.F150.

$\mathrm{X}-123.823$

$\mathrm{X}-124.375 \mathrm{Y}-93.708$

Y-.735

$\mathrm{X}-123.818 \mathrm{Y}-.62$

$\mathrm{X}-.781 \mathrm{Y}-.625$

$\mathrm{X}-.625 \mathrm{Y}-.709$

$\mathrm{Y}-93.735$

$\mathrm{X}-.835 \mathrm{Y}-94.259$

$\mathrm{X}-62.329$

X-62.372Y-94.248

$\mathrm{X}-62.443 \mathrm{Y}-94.171$

$\mathrm{X}-62.486 \mathrm{Y}-94.159$

$\mathrm{X}-123.782$

$\mathrm{X}-124.275 \mathrm{Y}-93.666$

Y-.809

$\mathrm{X}-123.77 \mathrm{Y}-.716$

$\mathrm{X}-123.256 \mathrm{Y}-.725$

$\mathrm{X}-.807$

X-.725Y-.769

$\mathrm{Y}-93.716$

X-.902Y-94.159

$\mathrm{X}-62.313$

$\mathrm{Z}-6.875$

G00Y-46.488

Z-10.575

G01Z-11.075

\author{
$\mathrm{X}-69.367 \mathrm{Y}-46.382$ \\ $\mathrm{X}-69.305 \mathrm{Y}-45.26$ \\ $\mathrm{X}-69.251 \mathrm{Y}-44.647$ \\ $\mathrm{X}-69.235 \mathrm{Y}-43.972$ \\ X-69.244Y-43.585 \\ $\mathrm{X}-69.267 \mathrm{Y}-43.215$ \\ $\mathrm{X}-69.305 \mathrm{Y}-42.869$ \\ $\mathrm{X}-69.371 \mathrm{Y}-41.668$ \\ $\mathrm{X}-69.374 \mathrm{Y}-35.589$ \\ Z-7.075 \\ G00X-69.376Y-46.008 \\ Z-10.675 \\ G01Z-11.175 \\ $\mathrm{X}-69.35 \mathrm{Y}-45.539$ \\ X-69.316Y-44.328 \\ $\mathrm{X}-69.326 \mathrm{Y}-43.215$ \\ $\mathrm{X}-69.376 \mathrm{Y}-42.091$ \\ $\mathrm{X}-69.374 \mathrm{Y}-35.72$ \\ Z-7.275 \\ G00X-69.375Y-45.539 \\ Z-10.775 \\ G01Z-11.275 \\ $\mathrm{X}-69.366 \mathrm{Y}-45.081$ \\ $\mathrm{X}-69.35 \mathrm{Y}-43.972$ \\ $\mathrm{X}-69.376 \mathrm{Y}-42.799$ \\ $\mathrm{X}-69.374 \mathrm{Y}-35.851$ \\ Z5. \\ M30 \\ $\%$
}

\section{For Cavity2}

Creating Workpiece

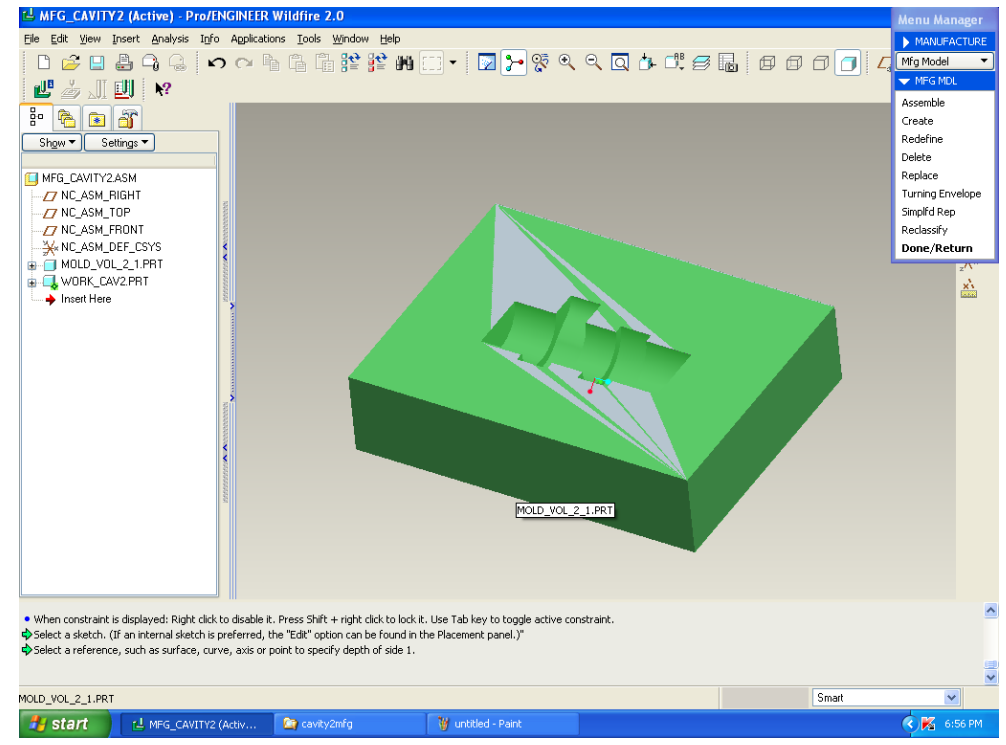

Set up the machine tool by selecting type of machine, cutting tool, Machine zero and retract.

For roughing, Select NC sequence - Machining - Volume - Done - Select tool and enter parameters like Cut feed, Step depth, Step over, Profile stock allow, rough stock allow, scan type and spindle speed.

Create volume.

Select Playpath 


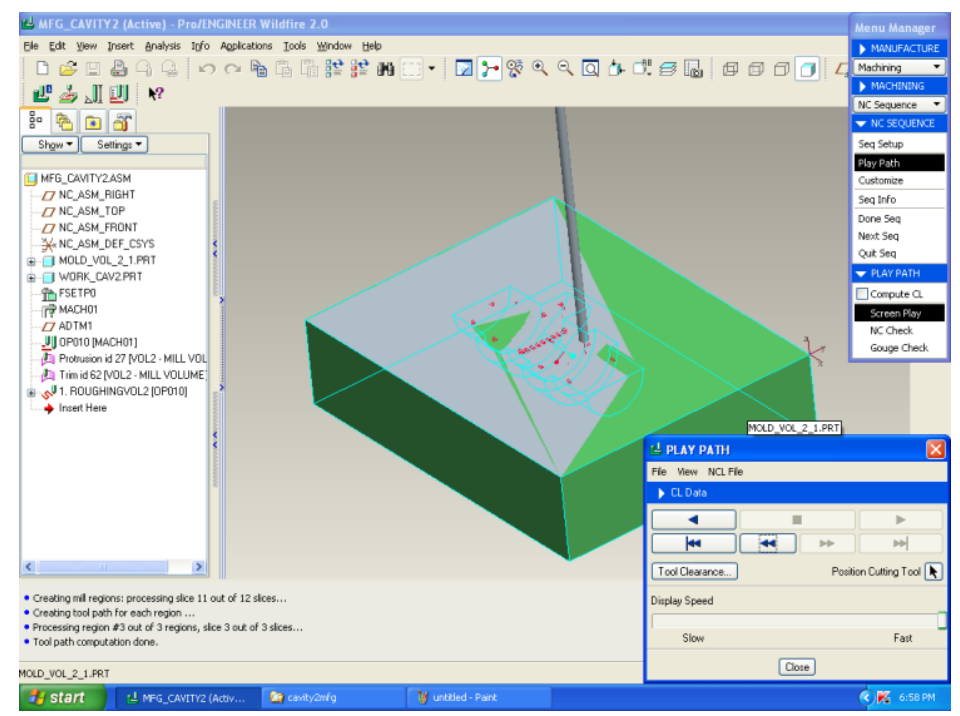

Machining $\rightarrow$ CL data $\rightarrow$ NC sequence $\rightarrow$ sequence $\rightarrow$ file $\rightarrow$ MCD file.

Done. Enter name . ok. Done.

\section{NC Program for roughing}

\section{$\%$}

G71

$\mathrm{O} 0003$

(D:Icamshaft_150cclroughingvol2.ncl.1)

N0010T1M06

S3500M03

G00X-71.37Y-32.627

G43Z5.H01

$\mathrm{Z} 1.5$

G01Z-1.F300.

$\mathrm{X}-77.5$

$\mathrm{Y}-33.618$

$\mathrm{X}-71.37$

$\mathrm{Y}-34.609$

$\mathrm{X}-77.5$

Y-35.599

$\mathrm{X}-71.37$

Y-36.59

$\mathrm{X}-77.5$

$\mathrm{Y}-37.581$

$\mathrm{X}-71.37$

$\mathrm{Y}-38.571$

$\mathrm{X}-77.5$

Y-39.562

$\mathrm{X}-71.37$

Y-39.97

G03X-71.302Y-40.552I2.504J-.002

G01X-77.568

G02X-78.055Y-41.543I-2.436J.58

G01X-70.815

G03X-68.87Y-42.475I1.949J1.571

G01X-57.74

Y-53.595

$\mathrm{X}-49.11$

Y-54.515
X-55.24

Y-55.436

$\mathrm{X}-49.11$

Y-56.356

X-55.24

X-49.11

Y-45.314

$\mathrm{X}-55.24$

Y-56.356

Y-54.463

Z-12.

$\mathrm{X}-49.11$

Y-53.556

$\mathrm{X}-55.24$

Y-52.649

$\mathrm{X}-49.11$

Y-51.742

X-55.24

Y-50.835

$\mathrm{X}-49.11$

Y-49.928

X-55.24

Y-49.021

$\mathrm{X}-49.11$

Y-48.114

$\mathrm{X}-55.24$

Y-47.207

X-49.11

$\mathrm{X}-55.24$

Y-54.463

$\mathrm{X}-49.11$

Y-47.207

Z5.

M30

$\%$ 


\section{For finishing,}

Select NC sequence - Machining - Finishing - Done - Select tool and enter parameters like Cut feed, Step depth, Step over, Profile stock allow, scan type and spindle speed.

Create volume.

Select Playpath

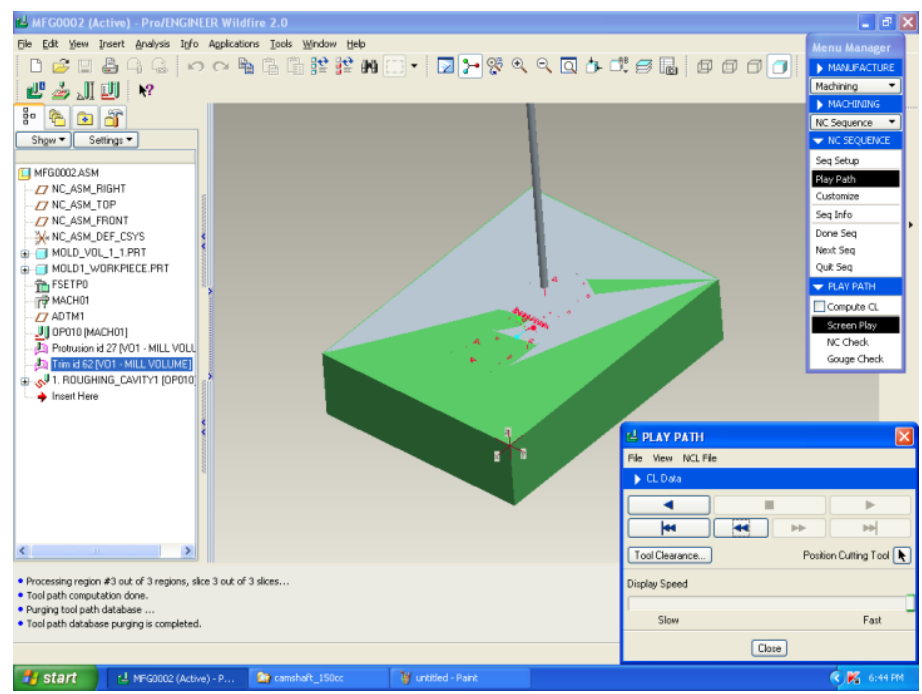

After completing Playpath, Select NC check

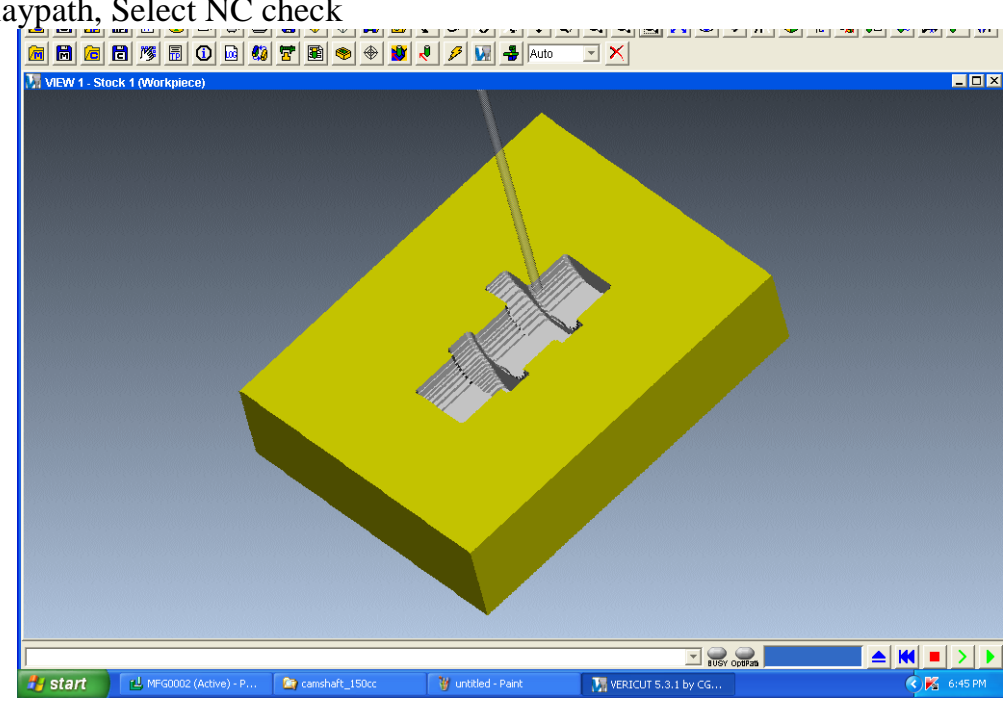

Machining $\rightarrow$ CL data $\rightarrow$ NC sequence $\rightarrow$ sequence $\rightarrow$ file $\rightarrow$ MCD file.

Done. Enter name . ok. Done.

\section{NC Program for Finishing}

$\%$

G71

O0004

Y-93.735

X-.835Y-94.259

$\mathrm{X}-62.329$

(D:Icamshaft_150cclfinishing_cam_cavity2.ncl.1)

$\mathrm{X}-62.372 \mathrm{Y}-94.248$

N0010T1M06

S7500M03

G00X-62.329Y-94.259

$\mathrm{X}-62.443 \mathrm{Y}-94.171$

$\mathrm{X}-62.486 \mathrm{Y}-94.159$

$\mathrm{X}-123.782$

G43Z5.H01

Z.35

G01Z0.F50.

$\mathrm{X}-123.823$

$\mathrm{X}-124.375 \mathrm{Y}-93.708$

$\mathrm{X}-124.275 \mathrm{Y}-93.666$

Y-.809

$\mathrm{X}-123.77 \mathrm{Y}-.716$

Y-.735

$\mathrm{X}-123.818 \mathrm{Y}-.62$

$\mathrm{X}-.781 \mathrm{Y}-.625$

X-.625Y-.709

$\mathrm{X}-123.256 \mathrm{Y}-.725$

$\mathrm{X}-.807$

X-.725Y-.769

$\mathrm{Y}-93.716$

X-.902Y-94.159

X-.97Y-94.059 
$\mathrm{X}-62.297$

$\mathrm{X}-62.34 \mathrm{Y}-94.048$

$\mathrm{X}-62.411 \mathrm{Y}-93.971$

X-62.454Y-93.959

$\mathrm{X}-123.699$

$\mathrm{X}-124.075 \mathrm{Y}-93.583$

Y-.965

$\mathrm{X}-123.673 \mathrm{Y}-.91$

$\mathrm{X}-123.268 \mathrm{Y}-.925$

X-.925Y-.929

$\mathrm{Y}-93.678$

X-1.038Y-93.959

$\mathrm{X}-62.281$

X-62.324Y-93.948

G01Z-10.975

$\mathrm{X}-69.307 \mathrm{Y}-52.792$

$\mathrm{X}-69.236 \mathrm{Y}-52.324$

$\mathrm{X}-69.183 \mathrm{Y}-51.866$

$\mathrm{X}-69.15 \mathrm{Y}-51.432$

$\mathrm{X}-69.133 \mathrm{Y}-50.756$

$\mathrm{X}-69.143 \mathrm{Y}-50.37$

$\mathrm{X}-69.166 \mathrm{Y}-50$.

$\mathrm{X}-69.242 \mathrm{Y}-49.306$

$\mathrm{X}-69.305 \mathrm{Y}-48.923$

$\mathrm{X}-69.376 \mathrm{Y}-47.991$

$\mathrm{Y}-42.243$

Z-6.875

G00Y-53.273

$\mathrm{Z}-10.825$

G01Z-11.075
$\mathrm{X}-69.367 \mathrm{Y}-53.167$

$\mathrm{X}-69.305 \mathrm{Y}-52.045$

$\mathrm{X}-69.251 \mathrm{Y}-51.432$

$\mathrm{X}-69.235 \mathrm{Y}-50.756$

$\mathrm{X}-69.244 \mathrm{Y}-50.37$

$\mathrm{X}-69.267 \mathrm{Y}-50$.

$\mathrm{X}-69.305 \mathrm{Y}-49.654$

$\mathrm{X}-69.371 \mathrm{Y}-48.453$

$X-69.373 Y-42.366$

Z-7.075

G00X-69.376Y-52.793

Z-10.925

G01Z-11.175

$\mathrm{X}-69.35 \mathrm{Y}-52.324$

$\mathrm{X}-69.316 \mathrm{Y}-51.113$

$\mathrm{X}-69.326 \mathrm{Y}-50$.

$\mathrm{X}-69.376 \mathrm{Y}-48.876$

$\mathrm{Y}-42.497$

Z-7.275

G00X-69.375Y-52.324

Z-11.025

G01Z-11.275

$\mathrm{X}-69.366 \mathrm{Y}-51.866$

$\mathrm{X}-69.35 \mathrm{Y}-50.756$

$\mathrm{X}-69.376 \mathrm{Y}-49.583$

$\mathrm{X}-69.374 \mathrm{Y}-42.629$

Z5.

M30

$\%$

\section{COST ESTIMATION OF DIE COMPONENT NAME - CAMSHAFT}

\begin{tabular}{|c|c|c|c|}
\hline $\begin{array}{c}\text { S. } \\
\text { No }\end{array}$ & Part Name & Material Specification & Price (Rs.) \\
\hline 1 & Core plate & $200 \times 150 \times 35 \mathrm{~mm}=6.18 \mathrm{~kg}$ (Material used is EN28) & $1,452 /-$ \\
\hline 2 & Cavity plate & $128.40 \times 60 \times 25 \mathrm{~mm}=1.41 \mathrm{~kg}$ (Material used is EN28) & $332 /-$ \\
\hline 3 & Core back plate & $200 \times 150 \times 35 \mathrm{~mm}=6.181$ (Material used is mild steel) & $1,452 /-$ \\
\hline 4 & Cavity back plate & $200 \times 150 \times 35 \mathrm{~mm}=6.12 \mathrm{~kg}$ (Material used is mild steel) & $435 /-$ \\
\hline 5 & $\begin{array}{l}\text { Ejector plate \& retainer } \\
\text { plate }\end{array}$ & $150 \times 120 \times 15 \mathrm{~mm}=2.11 \mathrm{~kg}$ (Material used is mild steel) & $498 /-$ \\
\hline 6 & Ejector pins & Qty-3 (Material used is OHNS) & $2,542 /-$ \\
\hline 7 & Pillar & Qty-4 (Material used is EN8) & $274 /-$ \\
\hline 8 & Retainer pin & Qty-8 (Material used is carbon steel) & $6,778 /-$ \\
\hline 9 & Retainer Plate & Qty-1 (Material used is mild steel) & $497 /-$ \\
\hline 10 & Space Housing & 200x150x85mm, Qty-2 (Material- EN8) & $4,423 /-$ \\
\hline 11 & Space Screw & Material- EN8 & $1,441 /-$ \\
\hline \multicolumn{3}{|r|}{ Total Material Cost $=20 \%$ Allowance } & $\begin{array}{r}20,124 /- \\
+\quad 4,024.8\end{array}$ \\
\hline & & TOTAL: & Rs. 24148.8 \\
\hline
\end{tabular}

\begin{tabular}{|c|l|r|r|}
\hline S. No & \multicolumn{1}{|c|}{ Part name } & \multicolumn{1}{c|}{$\begin{array}{c}\text { Machining cost } \\
\text { No.of hrs }\end{array}$} & Amount (Rs.) \\
\hline 1 & Primary machining & $7,500 /-$ \\
\hline 2 & Core & 90 & $25,000 /-$ \\
\hline 3 & Cavity & $30,000 /-$ \\
\hline 4 & Guide pillar & Cylindrical grinding & \\
\hline 5 & Heat treatment for core, cavity, runners, overflows & $3000 /-$ \\
\hline 6 & Polishing for core, cavity, runners & $25,000 /-$ \\
\hline 7 & Chrome plating for core, cavity in pattern area & $3,000 /-$ \\
\hline \multicolumn{1}{|c|}{ Total } & $\mathbf{1 , 2 5 , 5 0 0 / -}$ \\
\hline
\end{tabular}


1. Material cost

2. Machining cost

3. Transportation

4. Risk cost ( $15 \%$ of material \& machine)

5. Profit ( $20 \%$ of above 4$)$

\section{TOTAL DIE COST}

$=$ Rs. 24,148.8/-

$=$ Rs. $1,25,500 /-$

= Rs. $2,000 /-$

$=$ Rs.22,447/-

$=$ Rs.30,419/-

Total cost $\quad=$ Rs.2,04,515/-

\section{Conclusions}

In this paper first we done designed a camshaft using theoretical calculations for the 150cc petrol engine. In next step, we have modeled a camshaft according to design calculations. We have added the shrinkage allowance. We have extracted core and cavity for camshaft. We have prepared the total mould base according to standards. We have done manufacturing process for the camshaft and generated CNC programming. We are concluding that we designed the complete mould base which is ready to go for production. We have learnt how to design casting tool. We have also estimated cost of manufacturing of die for camshaft. The total cost to manufacture the die of camshaft is Rs.2,04,515/-.

\section{References}

[1] Handbook of Die Design by Ivana Suchy

[2] Machine Design by R.S. Khurmi and J.K. Gupta, Eurasia Publishing House (P) Ltd., New Delhi

[3] Pro/Engineer WildFire 2.0 by Steven G. Smith

[4] Product Design and Manufacturing by R.C. Gupta and A.K. Chaitle

[5] Theory of Machines by P.L. Ballney, Khanna Publishing, New Delhi.

[6] Theory of Machines by R.S. Khurmi and J.K. Gupta, S.Chand \& Co., New Delhi.

[7] Theory of Machines by S.S. Rattan, Tata McGraw Hill, New Delhi. 